\title{
Aproximación a la gobernanza de las cuencas transfronterizas del Líbano y su geopolítica
}

\author{
Guillermina Elias*
}

\begin{abstract}
RESUMEN
El objetivo del presente artículo es analizar las cuencas transfronterizas entre la República del Líbano y los países ribereños, considerando aspectos de cooperación y conflicto, geopolíticos de la región árabe, así como gobernanza. Esto se complementa con la propuesta del paradigma de la Gestión Integrada de Recursos Hídricos (GIRH).

Tradicionalmente, la cuestión de recursos hídricos compartidos en la región árabe ha estado altamente politizada, así como las negociaciones de alto nivel entre gobiernos han sido críticas. Al mismo tiempo, esto genera preocupación sobre la justicia y la seguridad hídrica. La atención ha estado centrada en disputas de largo recorrido surgidas de la dependencia árabe en recursos hídricos superficiales originados (o controlados por) países no árabes.

El agua es uno de los recursos más preciados en Líbano, como en todo el mundo, en especial si se consideran los actuales y futuros escenarios de cambio climático. La crisis humanitaria de 1,5 millones de refugiados sirios en territorio libanés presiona en mayor medidasobre los servicios de agua y sobre los recursos; si bien dicha crisis hídrica antecede a la llegada de dichos refugiados y está marcada por la propia situación geopolítica.

El agua disponible discurre por ríos, lagos, embalses y aguas subterráneas. Los recursos hídricos de este país se encuentran bajo estrés debido a distintos factores: prácticas de manejo no sostenibles, aumento de la demanda desde todos los sectores, contaminación y gobernanza inefectiva (casi ausente) del agua.

El Líbano comparte las siguientes cuencas con países ribereños: el río Jordán, el río Orontes y el río Nahr Al Kabir. En lo que respecta a agua subterránea, la cadena montañosa de Anti-Líbano está ubicada en la frontera con Siria.

La promoción de la cooperación es crucial para el manejo de los recursos hídricos compartidos en esta región. En este sentido, una acción más cooperativa y un diálogo constructivo son necesarios para gestionar estos recursos compartidos, considerando la gobernanza del agua, los principios de la hidrodiplomacia y la GIRH.

Las preguntas que guían este estudio son conocer qué cuencas hídricas comparte el Líbano, cuáles son las características de las mismas, y si existen acuerdos internacionales que regulen su uso y aprovechamiento conjunto. En cuanto a la metodología utilizada, la siguiente investigación se basa en información de fuentes primarias y secundarias (investigaciones académicas, prensa especializada, estadísticas, entre otras). El análisis de datos es cualitativo y documental.

Este artículo comienza con una introducción a la administración del agua en los países árabes. A continuación, se proponen bases teóricas para el estudio de cuencas transfronterizas. Como aporte al marco teórico, se desarrollan los principios sobre cursos de agua compartidos en el Derecho Internacional. A continuación, se presentan las cuencas transfronterizas del país de origen fenicio. Finalmente, se proponen las conclusiones del estudio.
\end{abstract}

\section{Palabras clave}

República del Líbano; cuencas transfronterizas; geopolítica; gobernanza; cooperación; conflicto; agua.

\section{Tithe}

An approach to transboundary basins governance in Lebanon and its geopolitics

\section{Abstract}

The aim of the paper is to analyze the shared basins between Lebanon and riparians, considering cooperation and conflict, geopolitical aspects in the Arab region, as well as governance. This is complemented with the Integrated Water Resources Management (IWRM) approach.

Traditionally, the issue of shared water resources in the Arab region has been highly politicized as well as a critical feature of high-level negotiations between governments.

At the same time, it causes concerns about justice and security among the general public around the world in relation to the human right to water.Attention has largely been focused on long-standing disputes arising from Arab dependence on surface
* Guillermina

ELIAS,

Becaria doctoral en Relaciones Internacionales, Facultad de Ciencia Política y Relaciones Internacionales, Univ. Nacional de Rosario,Argentina; $y$ Grupo de Historia Ambiental, Instituto Argentino de Nivología, Glaciología y Ciencias Ambientales (IANIGLA), Consejo Nacional de Investigaciones Científicas y Técnicas (CONICET). Su principal línea de investigación es la política internacional de cuencas transfronterizas. Contacto: gelias@ mendoza-conicet. gob.ar

Recibido:

05/05/2020

Aceptado:

26/09/2020

\section{DOI:}

https://doi.org/I 0.15366/relacionesinternacionales2020.45.0 I I

Formato de citación recomendado:

ELIAS, Guillermina (2020). “Aproximación a la gobernanza de las cuencas transfronterizas del Líbano y su geopolítica”, Relaciones Internacionales, n 45 , pp. 25I-273. 
water resources originating from (or controlled by) non-Arab countries.

Water is one of the most precious resources in Lebanon and all around the world, especially considering current and future climate change scenarios. The effects of the humanitarian crisis with 1.5 million Syrian refugees in Lebanon, putting pressure on water services and resources cannot be diminished either. However, the water crisis affecting Lebanon predates the arrival of the Syrian refugees and it's signed by its geopolitical situation.

Available water includes rivers and springs, storage dams and groundwater. Lebanon's water resources are under stress due to several factors: unsustainable water management practices, increasing water demand from all sectors, water pollution, and ineffective water governance.

Lebanon shares the following basins with riparian countries: the Jordan River, the Orontes River basin, also known as the Al Asi River and the Nahr Al Kabir basin. Concerning to groundwater, the Anti-Lebanon Mountain range is located at the Lebanese-Syrian border.

Originating from the Anti-Lebanon and Mount Hermon mountain ranges, the Jordan River covers a distance of $223 \mathrm{~km}$ from north to south and discharges into the Dead Sea. The river has five riparians: Israel, Jordan, Lebanon, Palestine and Syria.The Jordan River headwaters (Hasbani, Banias and Dan) are fed by groundwater and seasonal surface runoff.

Water use in the Jordan River basin is unevenly developed. Palestine and Syria have no access to the Jordan River; hence their use of water resources from the river itself is nil. However, Syria has built several dams in the Yarmouk River sub-basin. Overall, the Jordan River basin has an estimated total irrigated area of 100,000- 150,000 ha of which around $30 \%$ is located in Israel, Jordan and Syria, $5 \%$ in Palestine and $2 \%$ in Lebanon.

Regarding to the main agreements, on 1953 and 1987 Jordan and Syria agreed on the use of the Yarmouk River, including the construction of the Wahdah Dam and 25 dams in Syria. The agreement also establishes a joint commission for the implementation of the provisions on the Wahdah Dam. On 1994, Israel and Jordan agreed on Annex II of the Treaty of Peace concerns water allocation and storage of the Jordan and Yarmouk Rivers, and calls for efforts to prevent water pollution as well as the establishment of a Joint Water Committee. Israel and Palestine (PLO) accepted on 1995 the Article 40 of the Oslo II political agreement states that Israel recognizes Palestinian water rights in the West Bank only and establishes the JointWater Committee to manage West Bank waters and develop new supplies. Palestinians are denied access to the Jordan River under this agreement.

Geopolitically, the question of water sharing in the Jordan River basin is inextricably linked to the ongoing conflicts between Israel and Syria, Israel and Lebanon, and Israel and Palestine, and while a wide range of issues are at stake, control over water in the basin has added to existing regional tensions.

The Orontes River basin, also known as the Al Asi River, is the only perennial river in Western Asia that flows north from Lebanon to Syria and Turkey, and drains west into the Mediterranean Sea. The river is mainly used for irrigation purposes with several agricultural projects planned in the three riparian countries. There is no basin-wide agreement between the three riparians, but there are several bilateral agreements in place on issues such as water allocation (Agreement between Lebanon and Syria on the distribution of water of Al Asi River, 1994) and the joint construction of infrastructure (Syria and Turkey). Orontes basin politics are heavily influenced by the status of Turkish-Syrian relations in general, and discussions over the sharing of the Euphrates River in particular. Syria and Turkey have not resolved the question of the disputed coastal province of Hatay (Iskenderun) through which the Orontes exits to the Mediterranean Sea.

On 1994, Lebanon and Syria reached an agreement on the distribution of Orontes River Water originating in Lebanese territory, which specifies water allocation between the two countries. On 2009, Syria andTurkey agreed on the Memorandum of Understanding concerning the construction of the joint Orontes River Friendship Dam.

The NahrAl Kabir basin rises from numerous springs in Syria and in the Lebanon Mountain range. It runs a westerly course forming a natural border between northern Lebanon and Syria. The river is severely polluted by widespread discharge of untreated sewage and uncontrolled solid waste disposal.The two countries cooperate on the basis of a 2002 water-sharing agreement, with several joint technical sub-committees tackling various issues related to the watershed.

On 2002, Lebanon and Syria reached the Agreement to share the water of the NahrAl Kabir and build a joint dam on the main stem.

Concerning to groundwater, the Anti-Lebanon Mountain range is located at the Lebanese-Syrian border between the Bekaa Plain in the west and the Damascus Plain in the east. The Anti-Lebanon is an important source of water, both locally and in the wider regional context, as it forms the source of a number of rivers in the Mashrek. Several large springs emanate from these aquifers and contribute to the Awaj, Barada, Litani, Orontes and (Upper) Jordan Rivers.

There are no water agreements in place for any part of the Anti-Lebanon Mountain range, nor for the three shared spring catchments. The two riparians coordinate shared water resources management issues through the Syrian-Lebanese Joint Committee for SharedWater, which also implements the agreements in place over the Nahr Al Kabir and the Orontes River. In this regard, enhancing cooperation between Lebanon and riparians countries is crucial to manage shared water resources in this water-scarce region. More cooperative action and constructive dialogue is needed to sustain these shared resources, considering water governance, hydrodiplomacy principles and the IWRM approach.

The questions that guide this study are to know which watersheds Lebanon shares with its neighboring countries, what their characteristics are, and if there are international agreements that regulate their use and joint development.

In reference to the techniques of data collection, the research process will collect information from primary and secondary sources (academic research, specialized press, statistical series and international surveys, among others). As regards the techniques of data analysis, the research will use the documentary analysis, qualitative data analysis.

This article is presented with an introduction to water management in Arab countries. Next, theoretical bases for the study of transboundary basins are proposed. As a contribution to the theoretical framework, the principles on shared watercourses in International Law are developed. Then, the transboundary basins of the country of Phoenician origin, Lebanon, are presented. Finally, the conclusions of the study are given.

\section{KEYWORDS}

Lebanese Republic; transboundary basins; geopolitics; governance; cooperation; conflict; water. 
“(...) Estás en las bondades que te brindan tus ríos, Litani y el Jordán, Orontes y Barada, que dispersan sus aguas hacia los cuatro rumbos: van al norte y al sur, al este y al oeste, así como tus hijos te llevan por el mundo sin que importen distancias, países, continentes (...)”.

\author{
"Líbano, un legado" \\ María Banura Badui de Zogbi \\ Mendoza, Argentina, 2018
}

Las aguas superficiales y subterráneas que cruzan fronteras internacionales presentan mayores desafíos para la estabilidad regional porque las necesidades hidrológicas a menudo pueden verse complicadas por consideraciones políticas. Si bien el potencial del conflicto es especialmente alto,la historia muestra que el agua puede catalizar el diálogo y la cooperación, incluso entre ribereños especialmente contenciosos, aquellos que viven a lo largo de un río o aquellos que comparten un acuífero (UNESCO IHP, 20I6).

De acuerdo al Artículo $N^{\circ}$ II de las Normas de Helsinki sobre los usos de las aguas de los ríos internacionales, la cuenca hidrográfica internacional es "el área geográfica que se extiende por el territorio de dos o más estados, delimitada por la línea divisoria del sistema de las aguas, incluyendo las aguas superficiales y subterráneas que fluyen hacia un término común" $\left(52^{\circ}\right.$ Conferencia de la Asociación de Derecho Internacional, 1966).

De unas doscientas sesenta y tres cuencas hidrográficas transfronterizas (Wolf, 2007; GWP e INBO, 2009) que hay en el mundo, constituyendo casi la mitad de la superficie de la Tierra (Naciones Unidas, 20I4), ciento cincuenta y cinco son compartidas entre dos estados, treinta y seis entre tres estados y veintitrés entre cuatro o más estados. Además de ello, se calcula que unos cincuentaestados poseen un $75 \%$ de su territorio ubicado en cuencas hidrográficas compartidas, mientras que alrededor de $45 \%$ de la población del mundo vive dentro de una u otra cuenca compartida (Aguilar e lza, 2009). La mitad de la población mundial depende diariamente de los recursos hídricos compartidos entre más de un país, ya sea de las aguas superficiales de ríos y lagos transfronterizos o bien de las aguassubterráneas contenidas en acuíferos que se extienden por varios países.

De acuerdo a la Asociación Mundial del Agua (GWP e INBO, 20I2, p.6), "la cuenca de un río, lago o acuífero es el espacio donde aparecen las interdependencias hidrológicas, sociales, económicas y medioambientales, así como donde el desarrollo, el manejo y la gestión integrada de los recursos hídricos y de los territorios tienen el potencial para gestionar eficientemente el recurso en cuencas transfronterizas, de la mano de la gobernanza cooperativa del agua y de una gestión participativa de la cuenca, atendiendo al principio de unidad de cuenca, y respetuosos de sus interacciones socioecosistémicas”. 
Dentro de cada cuenca o acuífero internacional, las demandas de los usuarios ambientales, domésticos y económicos tienden a aumentar continuamente, mientras que la cantidad de agua dulce en el mundo sigue siendo aproximadamente la misma que ha sido a lo largo de la historia. Dado el alcance de los problemas y los recursos disponibles para abordarlos, es vital evitar conflictos violentos por el agua. Las disputas son perjudiciales e interfieren con los esfuerzos para aliviar el sufrimiento humano, reducir la degradación ambiental y lograr el desarrollo sostenible.

El desarrollo de la capacidad para monitorear, predecir y prevenir las diferencias transfronterizas de agua, particularmente en los países en desarrollo, es clave para promover la seguridad humana y ambiental en las cuencas fluviales internacionales, independientemente de la escala en que ocurran. Sin embargo, el conflicto también puede arrojar resultados positivos, brindando oportunidades para el diálogo, una mayor comprensión mutua y mejores relaciones y planificación integrada (Keohane, I984; UNESCO IHP, 20I6).

Tradicionalmente, el tema de los recursos hídricos compartidos en la región árabe' ha sido altamente politizado, así como una característica crítica de las negociaciones de alto nivel entre gobiernos. Al mismo tiempo, es motivo de preocupación por la justicia y la seguridad entre el público en general en todo el mundo en relacióncon el derecho humano al agua ${ }^{2}$. La atención se ha centrado en gran medida en disputas de larga duración derivadas de la dependencia árabe de los recursos de aguas superficiales que se originan en (o están controlados por) países no árabes. La Academia y la comunidad internacional realizaron numerosos proyectos de investigación relacionados con la cuenca del río Jordán, que es el río más estudiado de la región (UN ESCWA y BGR, 20I3).

A pesar de ser un país relativamente rico en agua en el contexto del Medio Oriente, el agua es un recurso cada vez más escaso en el Líbano. Analizar lacooperación transfronteriza para la gestión sostenible de sus tres cursos de agua transfronterizos - los ríos Orontes, $\mathrm{Nahr} \mathrm{Al}$ Kabiry Hasbani-Wazzani (afluentes del Jordán) — así como los acuíferos transfronterizos compartidos entre el Líbano y los países vecinos, se ha vuelto cada vez más importante (UNECE, 2019).

\section{I.Algunas consideraciones sobre la gestión del agua en la región árabe}

La Estrategia Árabe para la Seguridad del Agua en la Región Árabe, adoptada por el Consejo Ministerial Árabe del Agua en 20I I, identifica el uso y la gestión de los recursos hídricos compartidos como un desafío central para el desarrollo sostenible en la región. Los objetivos centrales de la estrategia incluyen no solo la protección de los derechos de agua árabes en aguas compartidas con estados no árabes y en territorios ocupados, sino que también exige una mayor cooperación entre los estados árabes para gestionar los recursos hídricos compartidos en la región.

Resaltamos, particularmente, el origen fenicio del Líbano.

2 El 28 de julio de 2010, a través de la Resolución 64/292, la Asamblea General de las Naciones Unidas reconoció explícitamente el derecho humano al agua y al saneamiento, reafirmando que un agua potable limpia y el saneamiento son esenciales para la realización de todos los derechos humanos. La Resolución exhorta a los estados y organizaciones internacionales a proporcionar recursos financieros, a propiciar la capacitación y la transferencia de tecnología para ayudar a los países, en particular a los países en vías de desarrollo, a proporcionar un suministro de agua potable y saneamiento saludable, limpio, accesible y asequible para todos.

En noviembre de 2002, el Comité de Derechos Económicos, Sociales y Culturales había adoptado la Observación General N ${ }^{\circ}$ I5 sobre el derecho al agua, estableciendo que "el derecho humano al agua es indispensable para una vida humana digna". La Observación N I 5 también define el derecho al agua como "el derecho de cada uno a disponer de agua suficiente, saludable, aceptable, físicamente accesible y asequible para su uso personal y doméstico” (Elias, 2019). 
Dicha Estrategia se presentó a los actores y partes interesadas comprometidos, y se recibieron comentarios preliminares de gobiernos y expertos en la región, como parte de un proceso de gobernanza. La escasez de agua siempre ha formado un aspecto clave de la vida en la Península Arábiga, Mashrek (Levante)y Mesopotamia. Históricamente, las comunidades que viven en estas regiones áridas y semiáridas siempre compartieron el agua de ríos, manantiales y wadis ${ }^{3}$.

Después de la creación de los estados nacionales modernos en la primera mitad del siglo $\mathrm{XX}$, la mayoría de los principales ríos de la región cruzan las fronteras políticas y están compartidos entre los estados. Los avances tecnológicos y el desarrollo del riego a gran escala en la segunda mitad del siglo XX impulsaron los sectores del agua y la agricultura, alterando fundamentalmente las relaciones transfronterizas. La regulación de los principales ríos a menudo tuvo impactos negativos en los usuarios de aguas abajo, especialmente durante el llenado de embalses. Las represas a pequeña escala en afluentes y en áreas de captación también afectaron los flujos aguas abajo. Se extrajeron grandes cantidades de agua superficial y se desviaron cada vez más de la cuenca.A su vez, los flujos de retorno de proyectos agrícolas intensivos a gran escala contaminaron los ríos. La calidad del agua se deterioró, en particular a consecuencia del aumento de la salinidad, lo que limita el uso aguas abajo. Además, las tasas de crecimiento demográfico exponencial en toda la región causaron un fuerte aumento de la demanda (UN ESCWA y BGR, 20I3).

En el estudio conjunto de la Comisión Económica y Social de las Naciones Unidas para Asia Occidental (UN ESCWA, por sus siglas en inglés) y ellnstituto Federal de Geociencias y Recursos Naturales (BGR, por sus siglas en alemán) (20l3), se destacan importantes observaciones relacionadas con el estado y la evaluación de los recursos hídricos compartidosde la región. Estas características sintetizan y consolidan algunos de los principales problemas relacionados con la identificación, el estado, el uso y la gestión de los recursos hídricos compartidos ${ }^{4}$ :

I) La cantidad y la asignación de agua dominan el discurso sobre los recursos hídricos compartidos en esta región escasa de agua: al igual que en otras regiones áridas y semiáridas, la escasez de agua en Asia occidental ha dado lugar a un enfoque de gestión del suministro que busca aprovechar todos los recursos hídricos disponibles y que prioriza la asignación cuantitativa del agua. Los países ribereños están más decididos a dividir los recursos hídricos de la región que a compartirlos. Tanto en el nivel del discurso como en los acuerdos, la atención se centra en la cantidad de agua disponible, no en los beneficios potenciales derivados de su uso compartido.

2) La calidad del agua se deteriora rápidamente: el problema del deterioro de la calidad del agua en toda la región se ve eclipsado por las preocupaciones sobre la cantidad. Sin embargo, el aumento de los niveles de contaminación y salinidad de los recursos de aguas superficiales y subterráneas está afectando cada vez más a la capacidad de utilizar los escasos recursos hídricos disponibles en la región, y está aumentando las tensiones entre los países ribereños. Además, si bien los ministerios ambientales consideran la necesidad de flujos ambientales mínimos para mantener los ecosistemas, este problema rara vez se incorpora en la planificación nacional del manejo del agua en la región.

3 En árabe o hebreo, curso seco de una corriente fluvial (IDR, s/f).

A los fines de este estudio, se lo considera como sinónimo de transfronterizos. 
3) La falta de datos precisos dificulta la gestión conjunta de los recursos hídricos: el agua sigue siendo un tema delicado en la región árabe y el intercambio de datos entre países ribereños es limitado. Como resultado, no existe una comprensión común del estado y el desarrollo de la disponibilidad, el uso y las tendencias del agua. A nivel nacional, a menudo faltan datos, son incompletos o inaccesibles, particularmente cuando se trata del uso del agua, que rara vez se mide. A nivel regional, los datos de diferentes países pueden ser contradictorios, a menudo porque no existen estándares unificados para medir los cambios hidrológicos. El hecho de que la cooperación entre países ribereños sea limitada impide aún más el desarrollo de una visión común sobre la gestión compartida de estos recursos.

4) Existe cooperación sobre el agua compartida, pero nunca abarca toda la cuenca: la prolongada inestabilidad política en la región ha obstaculizado la cooperación exitosa en toda la cuenca. No hay un solo acuerdo sobre los recursos hídricos compartidos en el Medio Oriente que abarque toda una cuenca. Los acuerdos bilaterales existentes se centran en la asignación de agua, con énfasis en el desarrollo y uso de la infraestructura. La calidad del agua no se aborda en estos acuerdos. No existen asociaciones de cuencas hidrográficas, por lo que la limitada cooperación bilateral sobre aguas superficiales se realiza a través de comités técnicos y proyectos locales.

5) No existe un solo acuerdo sobre los recursos compartidos de agua subterránea en la región: no existen acuerdos específicos sobre recursos compartidos de agua subterránea, aunque en algunos casos los acuerdos bilaterales incluyen disposiciones relacionadas con el agua subterránea. Los acuíferos a menudo no están claramente delimitados y, por lo tanto, en ocasiones los países ribereños no los reconocen como compartidos, lo que dificulta la cooperación.

6) El agua subterránea de la región es, en gran parte, no renovable y los acuíferos se están agotando rápidamente: su desarrollo masivo durante los últimos 30 años ha llevado al agotamiento de los acuíferos y a cambios hidrogeológicos sin precedentes, que amenazan la sostenibilidad del uso del agua subterránea.Además, las implicaciones transfronterizas de la alta abstracción generalmente se descuidan. En algunos casos, la explotación de los acuíferos compartidos se desarrolla tan rápidamente que estos pueden agotarse antes de ser reconocidos como un recurso compartido.

7) El agua subterránea juega un papel importante en las cuencas de agua superficial, un vínculo que a menudo se pasa por alto: el vínculo entre las aguas superficiales y subterráneas rara vez se explora. El agua subterránea forma el flujo de base de muchos ríos en esta región árida, incluidos el Jordán, Orontes y Nahr Al Kabir. Del mismo modo, la extracción excesiva de agua subterránea ha deprimido las capas freáticas y ha llevado a la desaparición de manantiales de agua dulce, lo que a su vez ha afectado los flujos de agua superficial. La extracción de agua subterránea y el desarrollo de sistemasde riego a gran escala también producen flujos de retorno, que contribuyen a la descarga de los ríos. La comprensión y la gestión de las cuencas compartidas pueden cambiar si se consideran juntas las aguas superficiales y subterráneas. 
8) Se requiere un nuevo pensamiento para un replanteo sobre los grandes sistemas acuíferos regionales desde una perspectiva compartida: una cooperación más estrecha sobre estos recursos requerirá la delimitación de unidades más manejables donde puedan producirseimpactos transfronterizos (UN ESCWA y BGR, 20I3).

\section{Propuestas teóricas para el estudio de cuencas transfronterizas}

La gestión de las cuencas transfronterizas puede analizarse ampliamente desde enfoques teóricos de las Relaciones Internacionales: geopolítica, cooperación y conflicto, y enfoques institucionales que reconstruyen mecanismos de gobernanza y capacidad institucional centrados en la participación de los interesados. Particularmente, y si bien no se profundiza en el presente artículo, resulta interesante el enfoque neoinstitucionalista (neoliberal), su consideración sobre los regímenes internacionales, $y$ el actual planteamiento sobre la existencia de un régimen internacional del agua.

El agua es un impulsor clave del desarrollo económico y social, mientras que también tiene una función básica en el mantenimiento de la integridad del medio ambiente natural. Sin embargo, el agua es solo uno de una serie de recursos naturales vitales y es imperativo que los problemas del agua no se consideren de forma aislada.

Cada vez más deben distribuirse suministros decrecientes entre demandas cada vez mayores. Motores como los cambios demográficos y climáticos aumentan aún más el estrés sobre los recursos hídricos; es urgente que los recursos hídricos transfronterizos no se queden atrás de estas circunstancias. Dado esto, el enfoque fragmentado tradicional ya no es viable y es esencial un enfoque más holístico para la gestión del agua (Naciones Unidas, 20l4).

Teniendo conocimiento sobre los antecedentes político-históricos de la región de Medio Oriente, es evidente que la misma ha estadomarcada por el binomio cooperación/conflicto. A continuación, compartimos algunos antecedentes teóricos sobre dicho debate, aplicado a nuestra área de estudio.

Algunas perspectivas internacionales en la dinámica de cooperación/conflicto de recursos hídricos compartidos, plantean que el conflicto y la cooperación son términos ambiguos usados para describir cómo los países interactúan entre sí en el uso compartido de los recursos hídricos transfronterizos (Warner y Zawahri, 20I2). Las varias formas de conflicto ocurren intercaladas con formas de cooperación. Ni todo el conflicto es malo, ya que puede reflejar una desigualdad en el uso de los recursos compartidos; ni siempre la cooperación es buena, pues puede resultar de relaciones asimétricas donde el estado menos fuerte es compelido a firmar un tratado desfavorable (Zeitoun y Mirumachi, 2008, 2010).

La gobernanza y gestión de las aguas transfronterizas ocurre en un escenario de asimetrías entre los actores, lo que puede influenciar el tipo de interacción entre ellos, el establecimiento de instituciones y el cumplimiento de las obligaciones. El incumplimiento de un tratado internacional puede indicar la existencia de un tipo de hidrohegemonía, en la cual los estados menos fuertes firman un acuerdo que no consideran favorable y después deciden no cumplirlo.Varias instituciones y acuerdos son creados para manejar los problemas y conflictos, pero no combaten las causas del 
conflicto (Zeitoun, Mirumachi y Warner; 20I I).

Yoffe, Wolf y Giordano (2003) apuntan que cambios rápidos dentro de una cuenca, físicos o institucionales, son indicadores más relevantes para la importancia de conflictos que el factor climático o el nivel de estrés hídrico en una cuenca.

Siegel (20I7), Villar y Ribeiro Costa (20II) esbozan que los instrumentos normativos e institucionales, particularmente en materia de cuencas transfronterizas, no han modificado de modo trascendental el contexto de cooperación en temas ambientales específicos, llegando a calificar de inefectivos en algunos casos.

Saguier (2017) complementa la propuesta anterior indicando que este aspecto se ve recrudecido por el hecho de que la política de cuencas transfronterizas presenta históricamente dinámicas de conflicto y cooperación.

Mello Sant'anna y Villar (20I5) aluden a que la cooperación internacional parece ser un requisito para la existencia de la gobernanza en las cuencas transfronterizas. Sin embargo, necesita ser analizada en su complejidad. La coexistencia de la cooperación y del conflicto explica por qué algunos casos de gobernanza en cuencas compartidas sufrieron retrocesos o se paralizaron.

Al anterior marco teórico, se suma la propuesta del paradigma de la Gestión Integrada de los Recursos Hídricos (GIRH), constituyéndose como un proceso sistemático desde el enfoque del desarrollo sostenible, que incluye la asignación y el monitoreo del uso de los recursos hídricos en el contexto de objetivos sociales, económicos y ambientales. Bajo este paradigma, es muy importante la construcción «de abajo hacia arriba» (bottom-up) a través de la participación de las comunidades y actores interesados. Este es un enfoque integral y holístico y procesos de múltiples partes interesadas para avanzar en la gobernanza y la gestión de los recursos hídricos para un desarrollo sostenible y equitativo.

Según Global Water Partnership (GWP), "la GIRH es un proceso que fomenta el desarrollo y la gestión coordinados del agua, la tierra y los recursos relacionados, con el objetivo de maximizar el bienestar económico y social resultante de forma equitativa, sin perjudicar la sustentabilidad de los ecosistemas vitales” (GWP, 2000, p. 22). La GIRH puede considerarse como la interpretación de la gestión de recursos hídricos con un enfoque holístico, teniendo en cuenta todas las dimensiones: el ciclo completo del agua, todos los sectores, y las escalas espaciales y temporales.

Este es el fundamento del enfoque de GIRH que ahora ha sido aceptado internacionalmente como el camino a seguir para el desarrollo y la gestión eficiente, equitativa y sostenible de los recursos hídricos limitados del mundo y para hacer frente a demandas conflictivas.

\section{I. Los principios sobre cursos de agua compartidos en el Derecho Internacional} La cooperación, además de ser un principio fundamental del Derecho Internacional de Aguas, se puede asumir bajo un enfoque distinto y entenderse como elemento clave para implementar 
soluciones que permitan fomentar una gobernanza efectiva de las cuencas compartidas, es decir, como un mecanismo mediante el cual los estados, a través de la autoregulación y la acción conjunta, trabajan en pos de consensos equilibrados sobre los distintos usos del río y de sus recursos (Aguilar e Iza, 2009).

La doctrina, la costumbre internacional y los distintos instrumentos del Derecho Internacional de Aguasincluyen, junto con la cooperación, la gestión integrada, la sostenibilidad y la participación entre sus principios específicos (Aguilar e Iza, 2009, pp. 25-28).

El 21 de mayo de 1997, la Asamblea General de Naciones Unidas, en su 5 I ${ }^{\circ}$ Sesión, aprobó la Resolución A/RES/5 I/229, adoptando la Convención sobre el Derecho de los Usos de los Cursos de Agua Internacionales para Fines distintos de la Navegación ${ }^{5}$. Los resultados de la votación en la Asamblea General dieron indicios del apoyo global a la Convención: cientotres votos a favor, tres en contra, veintisiete abstenciones y treinta y tres ausencias. La Convención se mantuvo abierta para su firma hasta el $2 \mathrm{I}$ de mayo de 2000 , entrando en vigor en agosto de 2014 .

La narrativa dominante fuera de la región otorga gran importancia a garantizar los derechos árabes del agua. Quizás esto también explique el apoyo temprano y relativamente generalizado de los países árabes a los instrumentos mundiales del Derecho Internacional de Aguas. De los 29 países que hoy son Parte en la Convención de las Naciones Unidas de 1997, ochoson de la región árabe. Siria, Jordania y Líbano fueron de los primeros en firmar, ratificar o acceder a este importante instrumento legal. Por el contrario, ninguno de los países ribereños no árabes ha firmado o se ha convertido en parte de la Convención. Líbano se adhirió a la Convención el 25 de mayo de $1999^{6}$, acontecimiento que brindó apoyopara la revisión del acuerdo con Siria sobre los ríos Orontes y NahrAl Kabir (UNECE, 2019).

Dicha Convención especifica, entre los derechos y deberes de los estados parte de una cuenca compartida o un curso de agua internacional, los siguientes: la utilización equitativa de las aguas, el deber de proteger las aguas de daños significativos, las obligaciones procesales relativas al intercambio de información, consulta y negociación; y la obligación emergente de proteger los ecosistemas de las cuencas compartidas (Naciones Unidas, 1997). Estos principios legales fundamentales, incluidas las prácticas intraestatales, dan forma a la denominada hidrodiplomacia.

Reforzando lo anterior, existen reglas de Derecho Internacional de naturaleza general y fundamental que gobiernan a los estados en relación con los cursos de aguas transfronterizos (Paisley, 2008; Rahaman, 2009, pp. 207-223):

a) Uso equitativo y razonable: obligación de los estados ribereños de asegurar proactivamente que el uso de las aguas sea razonable y equitativo con relación a los demás estados ribereños.

b) Participación equitativa: utilización en común de recursos hídricos compartidos para el logro de diversos objetivos.

c) Prevención del daño sensible: un estado no debe causar daño sensible a otro estado.

5 Texto de la Convención: https://legal.un.org/ilc/texts/instruments/english/conventions/8_3_1997.pdf

6 Estado de participantes: https://treaties.un.org/Pages/ViewDetails.aspx?src=TREATY\&mtdsg_no=XXVII-I2\&chapter=27\&lang=en 
d) Reglas concernientes a nuevos usos que afecten a un curso de agua: los estados deben notificar a los demás estados ribereños sobre usos futuros del agua, cuando éstos puedan dañarlos sensiblemente.

f) Principio de cooperación e intercambio de información: cada estado ribereño debe cooperar e intercambiar información y datos relativos al estado del curso de agua.

g) Reglas relativas a contaminación: los estados están obligados a prevenir, reducir y controlar la contaminación que pueda dañar a los demás estados ribereños.

En este marco, Líbano reafirmó su voluntad de convertirse en Parte de la Convención de la Comisión Económica de las Naciones Unidas para Europa (CEPE) sobre la Protección y el Uso de los Cursos de Agua Transfronterizos y los Lagos Internacionales (Convención del Agua) ${ }^{7} d u-$ rante la consulta nacional de alto nivel «La Convención del Agua: una oportunidad para el Líbano" celebrada en Beirut el II de abril de 2019.

Sobre la base de varios pasos clave emprendidos desde 2015 por las autoridades libanesas al considerar y estudiar la adhesión a la Convención del Agua, atendida por la CEPE, la consulta nacional ofreció una plataforma para que las partes interesadas discutan más a fondo las implicaciones, beneficios y oportunidades de unirse a la Convención, dado las necesidades y expectativas específicas del Líbano.

En este sentido, funcionarios libaneses destacaron el papel clave que podría desempeñar la Convención del Agua en la región para avanzar hacia una gestión más colectiva y cooperativa de las aguas transfronterizas. Además, señalaron que la Convención, con la cooperación como uno de sus pilares, presenta oportunidades para apoyar el desarrollo socioeconómico nacional y regional en una región propensa a sensibilidades geopolíticas, en el anhelo de reforzar la cooperación transfronteriza en materia de agua para la integración regional y la paz.

Esta consulta nacional de alto nivel fue coorganizada por el Ministerio de Energía y Agua del Líbano, la CEPE y la Asociación Mundial del Agua del Mediterráneo (GWP-Med), con el apoyo financiero de la Agencia Sueca de Cooperación Internacional para el Desarrollo (SIDA)(UNECE, 2019).

\section{La situación de los recursos hídricos compartidos en Líbano}

Los efectos de la reciente crisis humanitaria con 1,5 millones de refugiados sirios en Líbano, a los que se suman unos 650.000 refugiados palestinos, imponen presión sobre los servicios de agua y demás recursos. Sin embargo, la crisis del agua en este país antecede a la llegada de refugiados sirios y está marcada por la situación geopolítica del Líbano en Medio Oriente.

Una larga guerra civil (1975-1990), ausencia de inversión y de políticas sostenidas, episodios sostenidos de conflictos guiados por tensiones regionales y religiosas (confesionales), de-

\footnotetext{
Sobre la Convención de la CEPE sobre la Protección y el Uso de los Cursos de Agua Transfronterizos y los Lagos Internacionales: https:// www.unece.org/env/water.html

8 Otros países de la región de Medio Oriente y África del Norte, incluidos Irak, Jordania y Túnez, también han mostrado interés en adherirse
} a la Convención del Agua. 
sastres ambientales como la deforestación de los bosques de cedros milenarios, la catástrofe de derrame de petróleo de la central eléctrica de Jiyehdurante la guerra con Israel en 2006, sumada la reciente tragedia de explosiones en el puerto de Beirut el pasado 4 de agosto, han dañado el acceso a servicios básicos en pueblos y ciudades, en especial, la infraestructura hídrica del país (UNEP, 2007; Elias, 2014, 2016; Walnycki, 2018). En este marco, también debiera considerarse la conflictividad potencial entre Líbano e Israel por las reservas de petróleo y gas descubiertas en la cuenca Levantina (Barrington y Williams, 2018).

El agua disponible incluye ríos, termas, embalses y agua subterránea. De acuerdo al Ministerio de Ambiente de Líbano (20I2), los recursos hídricos de este país se encuentran bajo estrés dado distintos factores: prácticas de manejo no sostenibles, aumento de la demanda desde todos los sectores, contaminación y gobernanza inefectiva del agua.

Las fuerzas motrices que afectan calidad y cantidad de los recursos hídricos libaneses son el aumento de la población y la estructura por edades, la urbanización (88\% de la población vive en áreas urbanas), el crecimiento económico y, más recientemente, el cambio climático. Otros factores que afectan la disponibilidad del agua son la variabilidad interanual de las precipitaciones en las regiones más áridas de Líbano y la disminución de la cobertura y densidad nívea en la cordillera.

La gestión sostenible del agua es vulnerable a los impactos de la variabilidad climática y los cambios socioeconómicos. A pesar de ser un país relativamente rico en agua, el Líbano está experimentando episodios de sequía y escasez de agua(UN ESCWA y BGR, 20I3).

A continuación, se presentan los casos de cuencas compartidas entre el Líbano y los países ribereños, tanto de agua superficial (ríos Jordán, Orontes y Nahr El Kabir) como subterránea (Anti-Líbano). 


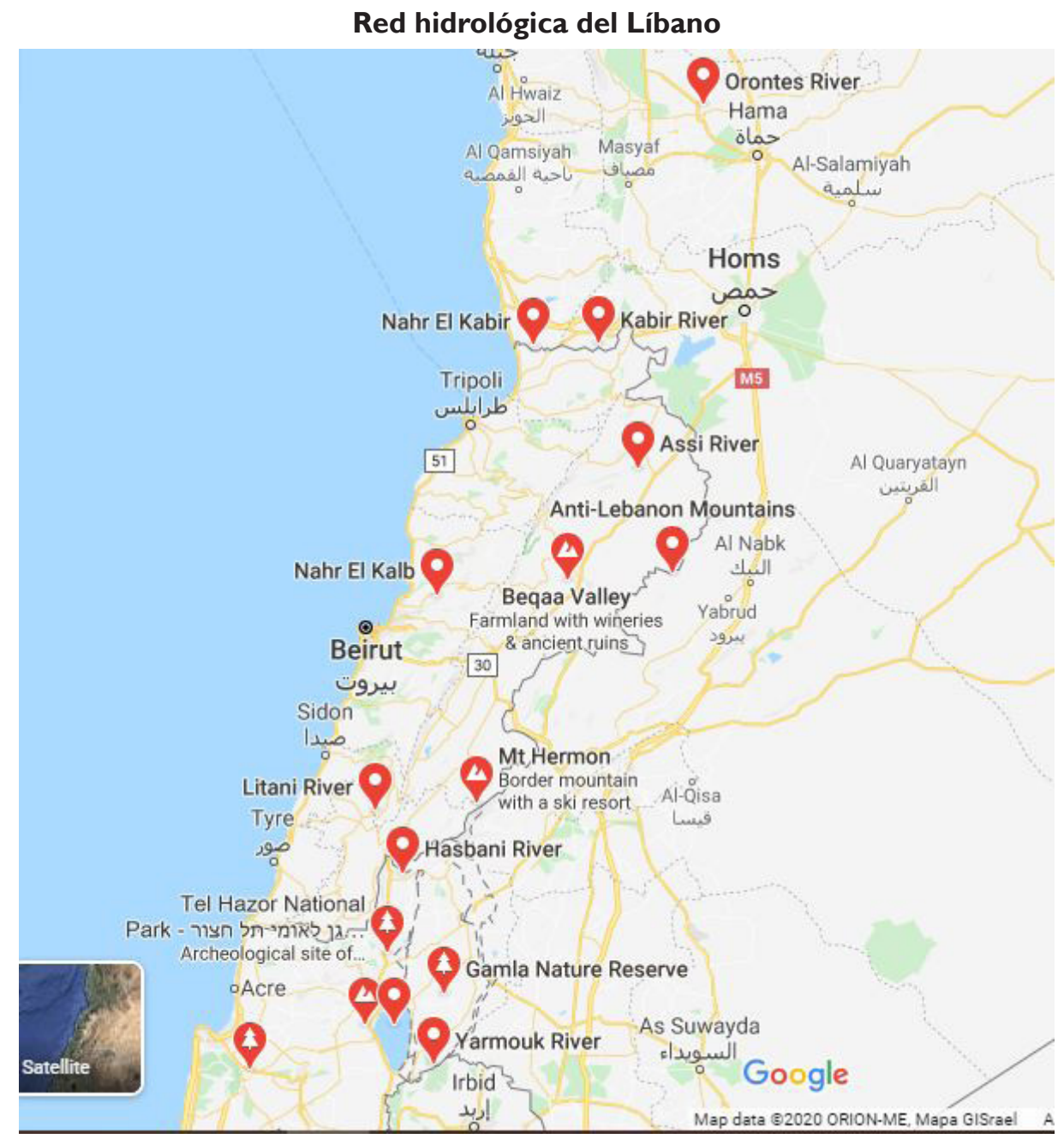

Fuente: Google Maps, 2020.

\section{I. Jordán}

Originario de las cadenas montañosas Anti-Líbano y Monte Hermón, el río Jordán cubre una distancia de $223 \mathrm{~km}$ de norte a sur y desemboca en el Mar Muerto. El río tiene cinco países ribereños: Israel, Jordania, Líbano, Palestina y Siria.

Las cabeceras del río Jordán (Hasbani, Banias y Dan) son alimentadas por el agua subterránea y la escorrentía superficial estacional. El río Jordán Inferior recibía originalmente su aportación principal desde la desembocadura del lago Tiberíades y el río Yarmouk, el afluente más grande, así como de varios wadis y acuíferos. El flujo del ríoAlto Jordán hacia el lagoTiberíades sigue siendo casi natural, pero las tasas de flujo en la parte aguas abajo del río han disminuido considerablemente en los últimos cincuenta años debido a la construcción de una serie de infraestructura y sistemas de derivación establecidos en la cuenca. Por ejemplo, el flujo histórico anual promedio del Yarmouk que se estimó en 450-500 mmª (millones de metros cúbicos por año) en la década de 1950 ha disminuido hoy a 83-99 mmª. La descarga anual actual del Bajo Río Jordán hacia el Mar Muerto se estima en $20-200 \mathrm{~mm}^{3} / \mathrm{a}$ en comparación con los históricos $1.300 \mathrm{~mm}^{3} / \mathrm{a}$.Además, la calidad del agua en el Bajo Jordán es muy baja. 
El uso del agua en la cuenca del río Jordán se desarrolla de manera desigual. Palestina y Siria no tienen acceso al mismo, por lo tanto, el uso de los recursos hídricos del río en sí es nulo. Sin embargo, Siria ha construido varias represas en la subcuenca del río Yarmouk. El país utiliza alrededor de $450 \mathrm{~mm}^{3} / \mathrm{a}$ de recursos de agua superficial y subterránea en la cuenca, principalmente para fines agrícolas. Las captaciones anuales en la subcuenca de Hasbani en el Líbano se estiman en $9-10 \mathrm{~mm}^{3} / \mathrm{a}$, y se utilizan principalmente para el suministro de agua doméstica.

Israel es el mayor usuario de agua de la cuenca del río Jordán, con una extracción anual de entre 580 y $640 \mathrm{~mm}^{3} / \mathrm{a}$. También es el único usuario de agua del lago Tiberíades. Jordania, por su parte, utiliza alrededor de $290 \mathrm{~mm}$ /a de agua de la cuenca del río Jordán. El agua desviada del río Yarmouk al Canal Rey Abdullah se usa para el riego de cultivos en el Valle del Jordán y para uso doméstico en Ammán. La cuenca del río Jordán tiene un área de riego total estimada de 100.000 a I50.000 ha, de las cuales alrededor del $30 \%$ se encuentra entre Israel, Jordania y Siria, el $5 \%$ en Palestina y el $2 \%$ en el Líbano.

La calidad del agua en el río Jordán se ha deteriorado severamente en las últimas décadas. $\mathrm{Si}$ bien las cabeceras no se ven afectadas. El Bajo río Jordán se compone principalmente de aguas residuales no tratadas y flujos de retorno agrícola, filtración de agua subterránea, así como agua de manantiales desviados hacia el río lejos del área del lago Tiberíades. El Bajo Río Jordán, en particular, está extremadamente contaminado. Otras preocupaciones ambientales incluyen las fluctuaciones del nivel del agua en el lago Tiberíades y el riesgo asociado de intrusión de agua salina desde aguas abajo, y, lo que es más importante, la disminución del Mar Muerto, que amenazan la estabilidad del ecosistema de la cuenca.

Desde principios del siglo $X X$, numerosos intentos de fomentar la cooperación entre los países ribereños de la cuenca se han visto obstaculizados por el conflicto político regional que continúa obstaculizando cualquier acuerdo sobre el agua en toda la cuenca.Varios acuerdos bilaterales han buscado fomentar la cooperación sobre el agua entre Israel y Jordania, e Israel y Palestina.

Con respecto a los principales acuerdos, en 1953 y 1987 Jordania y Siria acordaron el uso del río Yarmouk, incluida la construcción de la represa Wahdah y veinticinco represas en Siria. El acuerdo también establece una comisión conjunta para la implementación de las disposiciones sobre la presa Wahdah. En 1994, Israel y Jordania acordaron que el Anexo II del Tratado de Paz se refiere a la asignación y almacenamiento de agua de los ríos Jordan y Yarmouk, y pide esfuerzos para prevenir la contaminación del agua, así como el establecimiento de un Comité Conjunto del Agua. Israel y Palestina (OLP) aceptaron en 1995 el Artículo 40 del acuerdo político de Oslo II que establece que Israel reconoce los derechos de agua palestinos solo en Cisjordania y establece el Comité Conjunto del Agua para administrar las aguas de Cisjordania y desarrollar nuevos suministros. A los palestinos se les niega el acceso al río Jordán en virtud de este acuerdo.

Las preocupaciones clave sobre la cantidad y la calidad del agua se refieren a garantizar cantidades adecuadas de agua para todos los ribereños como un desafío clave en la cuenca dado el volumen relativamente pequeño de agua disponible y la gran población. El flujo de los ríos se ha reducido considerablemente a lo largo de los años como resultado del aumento de la explotación 
de los recursos hídricos en la cuenca. El rápido declive del Mar Muerto es un indicador de que el ecosistema de la región está en riesgo. La calidad del agua se deteriora rápidamente a lo largo del curso del río Jordán y su porción inferior muestra tasas extremadamente altas de salinidad y contaminación.

Geopolíticamente, la cuestión de compartir el agua en la cuenca del río Jordán está indisolublemente vinculada a los conflictos entre Israel y Siria, Israel y el Líbano, e Israel y Palestina. Así, el control sobre el agua en la cuenca se ha sumado a las históricas tensiones regionales (UN ESCWA y BGR, $2013)^{9}$.

\section{Ríos Hasbani y Wazzani, tributarios de la cuenca del Jordánen el Líbano}

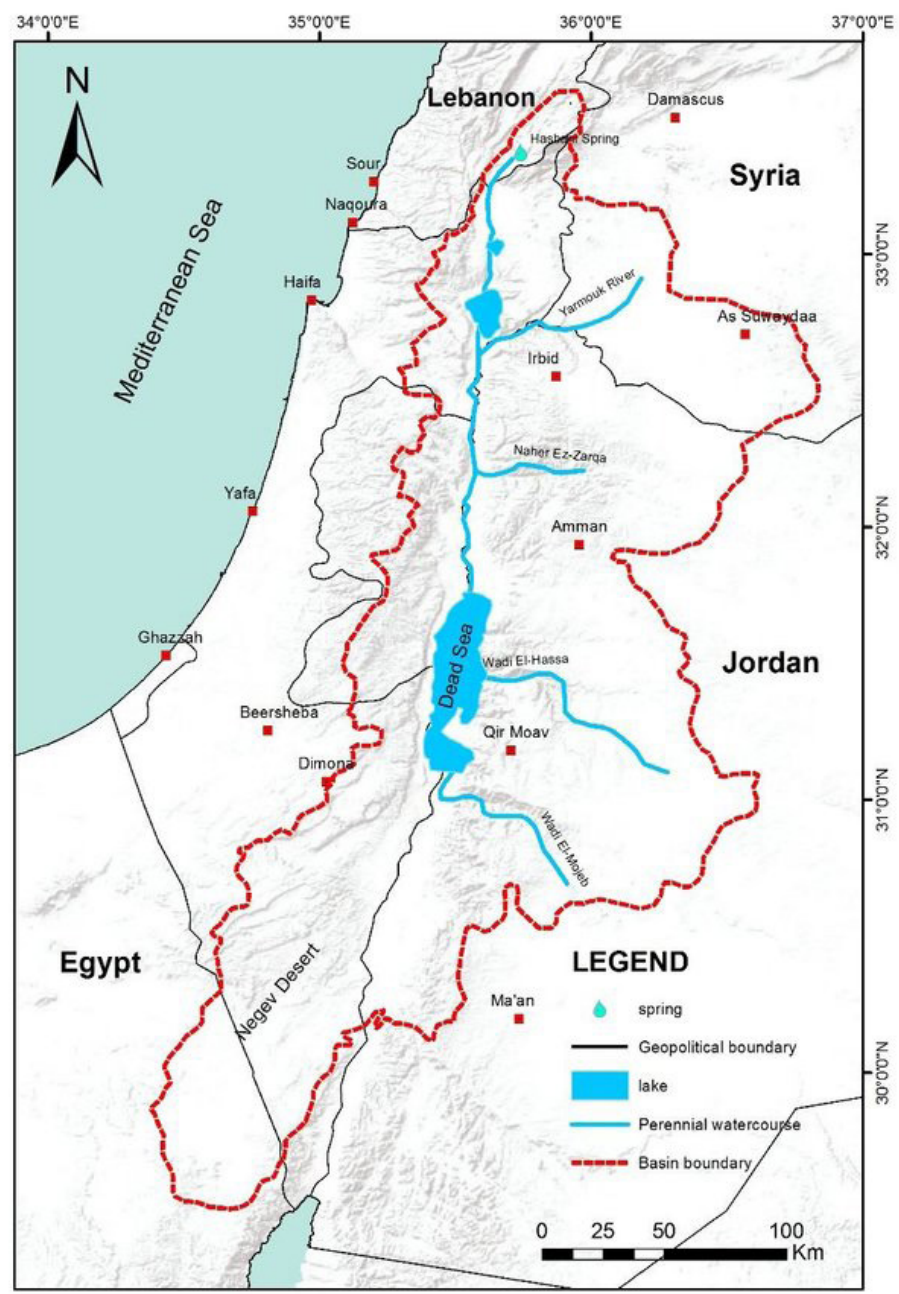

Fuente: Shaban, A. yHamzé, M. H. (20 I 7). Shared Water Resources of Lebanon. Nueva York: Nova Science Publishers, Inc. ISBN: 978-I-536 I 2-I 42-I. Recuperado de: https://www.researchgate.net/publication/3 19980038_Shared_Water_ Resources_of_Lebanon(03.05.20).

\footnotetext{
9 La traducción es propia.
} 
Descarga (discharge) mensual promedio de los ríos Hasbani y Wazzani

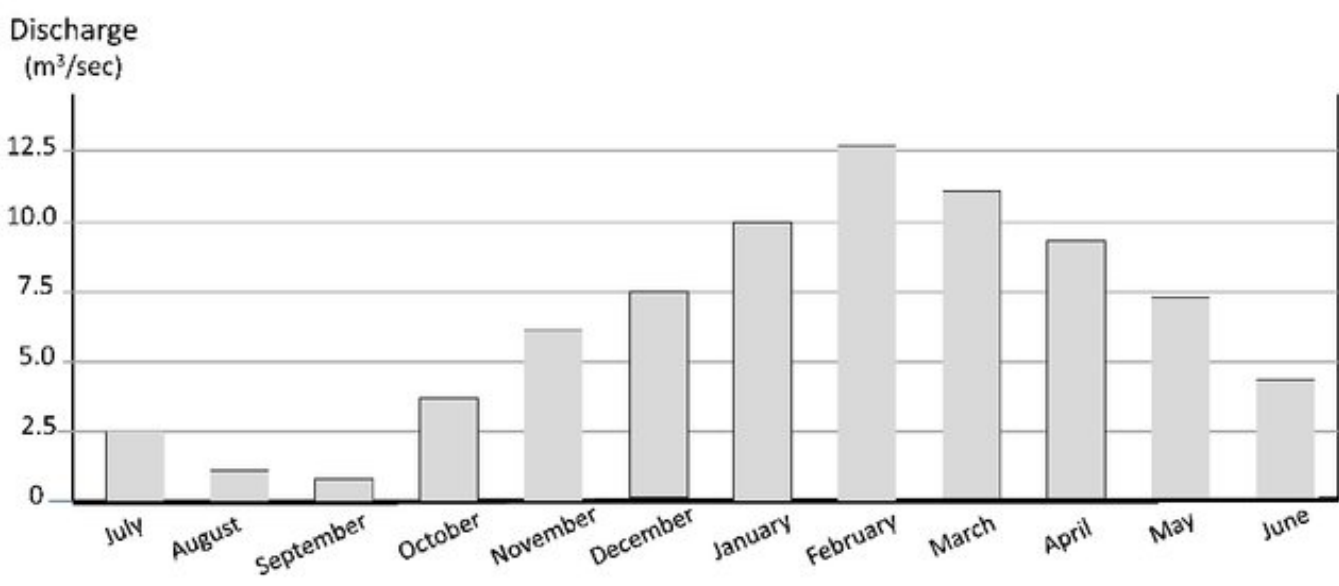

Fuente: Shaban y Hamzé, 2017.

\subsection{Orontes (Al Asi) ${ }^{10}$}

Fue llamado por muchos nombres a lo largo de la historia: el río Arnat, Hornet, Aurantus, Ornd, Maqlub, Mimas, Kabir y Orontes, que predominó porque corría de sur a norte en dirección opuesta a los ríos de la región.

La cuenca del río Orontes, también conocido como río AlAsi, es el único río perenne en el oeste de Asia que fluye hacia el norte desde el Líbano a Siria y Turquía. Se origina en las cimas del Valle de Bekaa en el Líbano para desembocar en el Mar Mediterráneo, en la bahía de Suwaidia.No tiene una sola fuente, sino más bien tres grupos de fuentes: las más importantes son Ain Al Zarqa y Shoghir y Hermel de las laderas de la cordillera occidental del Líbano, el grupo de fuentes de Al Labwah, Ain Falaki y Ras Baalbek de las estribaciones de las montañas.

Este río se utiliza principalmente para fines de riego con varios proyectos agrícolas planificados en los tres países ribereños. No existe un acuerdo para el conjunto de la cuenca entre los tres ribereños, pero existen varios acuerdos bilaterales vigentes sobre cuestiones como la asignación de agua (Acuerdo entre Líbano y Siria sobre la distribución de agua del río Al Asi, 1994) y la construcción conjunta de infraestructura (Siria-Turquía). La política de la cuenca del Orontes está fuertemente influenciada por el estado de las relaciones turco-sirias en general, y las discusiones sobre el intercambio del río Eufrates en particular. Siria y Turquía no han resuelto la cuestión de la disputada provincia costera de Hatay (Iskenderun) a través de la cual el Orontes sale al Mar Mediterráneo (UN ESCWA y BRG, 20I3; OregonStateUniversity, 20I6).

En 1994, Líbano y Siria llegaron a un acuerdo sobre la distribución del agua del río Orontes que se origina en territorio libanés, que especifica la distribución del agua entre los dos países. En 2009, Siria y Turquía acordaron el Memorando de Entendimiento relativo a la construcción conjunta de la Presa de la Amistad del río Orontes.

10 "El Rebelde", en español. Nombre heredado por su dirección opuesta a los ríos de la región. 
En cuanto a la cantidad y la calidad del agua, el río Orontes se usa intensamente en los tres países ribereños, principalmente para fines agrícolas. La implementación de proyectos de riego adicionales ejerce más presión sobre el recurso. Mientras que Líbano y Siria han acordado cuestiones de asignación de agua, Turquía y Siria no lo han hecho. No hay acuerdo entre los tres ribereños. En sus tramos medio e inferior, el Orontes está muy contaminado con efluentes no tratados que se descargan directamente en el cauce del río. Los problemas de calidad del agua no se han abordado en el contexto de la cooperación (UN ESCWA y BRG, 2013)".

\section{Cuenca del río Orontes}

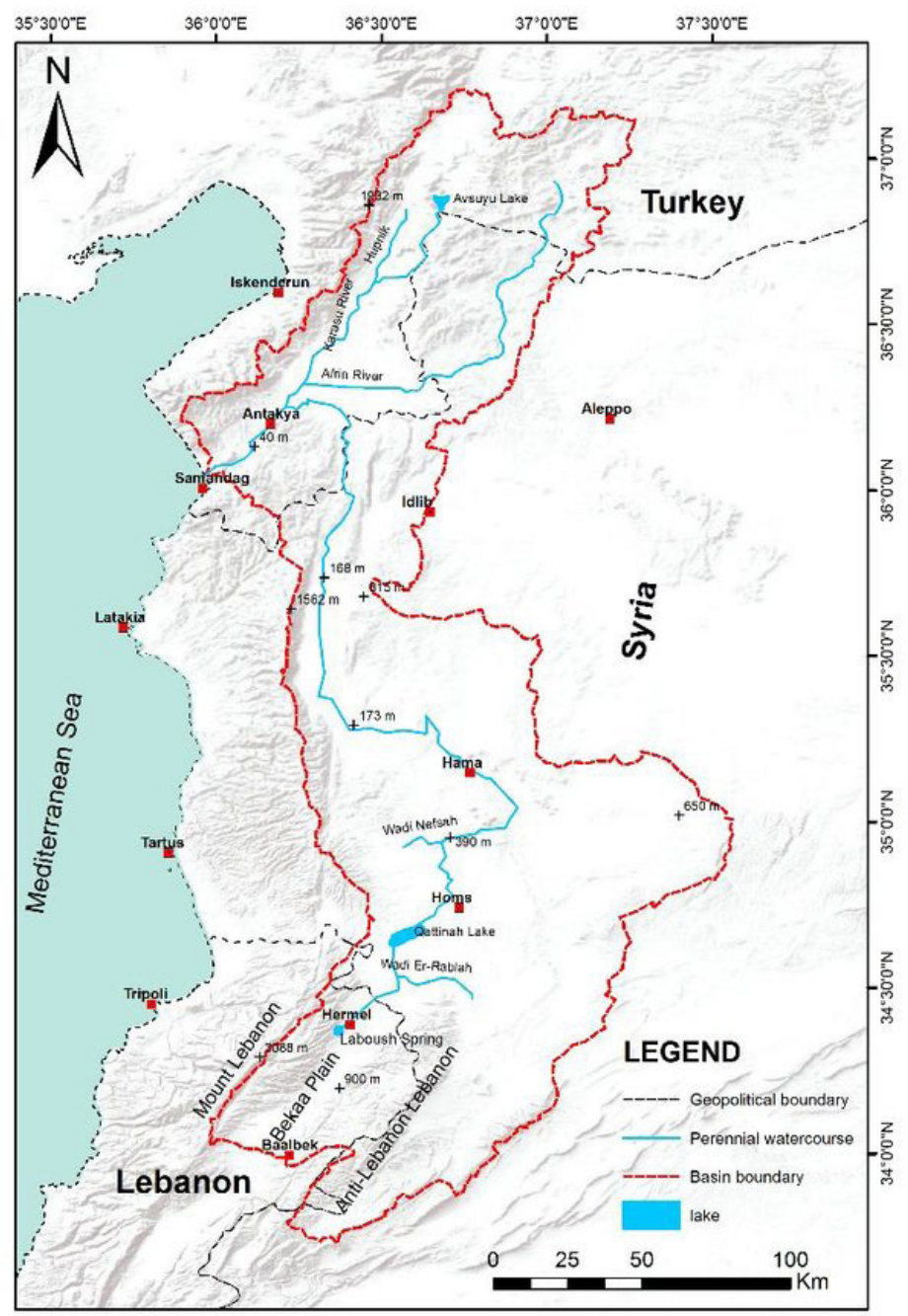

Fuente: Shaban y Hamzé, 2017.

\footnotetext{
"La traducción es propia.
} 


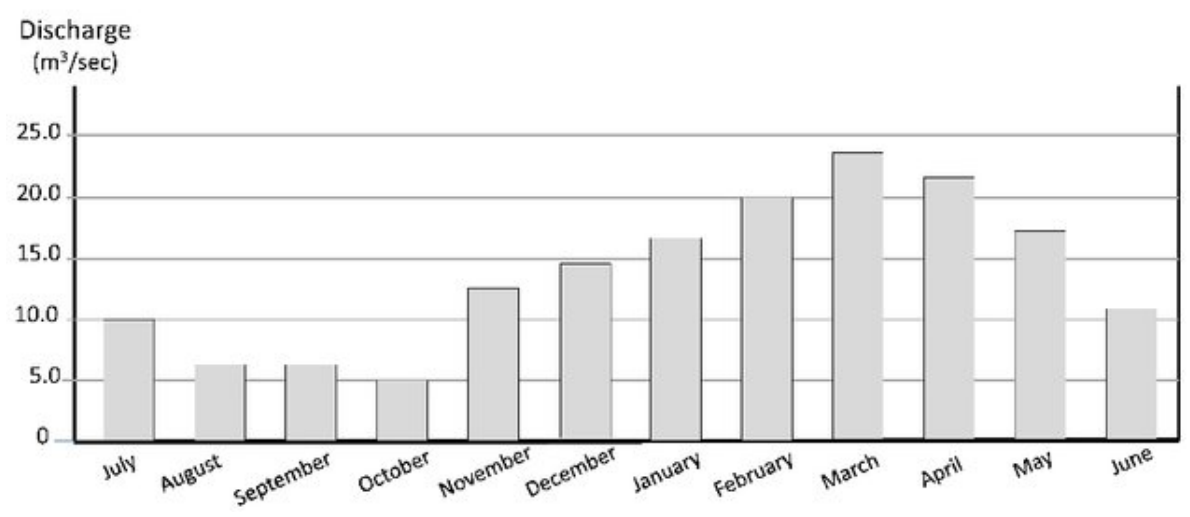

Fuente: Shaban y Hamzé, 2017.

\subsection{Nahr Al Kabir'2}

La cuenca de Nahr Al Kabir se eleva desde numerosos manantiales en Siria y en la cordillera del Líbano. Sigue un curso hacia el oeste formando una frontera natural entre el norte del Líbano y Siria. La degradación ambiental es un problema importante en la cuenca: el río está severamente contaminado por la descarga generalizada de aguas residuales no tratadas y la eliminación incontrolada de residuos sólidos. Otras amenazas incluyen inundaciones recurrentes y la propagación del jacinto de agua (planta acuática y especie invasora) a lo largo de todo el curso del río. Los dos países cooperan sobre la base de un acuerdo para compartir el agua en 2002, con varios subcomités técnicos conjuntos que abordan diversos temas relacionados con la cuenca.

En 2002, Líbano y Siria alcanzaron el acuerdo para compartir el agua del Nahr Al Kabir y construir una presa conjunta en el tramo principal.

Una preocupación clave es que el Nahr Al Kabir está severamente contaminado. La ausencia de prácticas agrícolas sólidas, la descarga incontrolada de aguas residuales no tratadas y la eliminación aleatoria de residuos sólidos por parte de ambos ribereños ha llevado a una degradación ambiental generalizada y representa una grave amenaza para la salud pública. Las preocupaciones sobre la calidad del agua no se abordan en el acuerdo de agua sirio-libanés (UN ESCWA y BRG, 20I3).

12 “Río El Grande”, en español. 


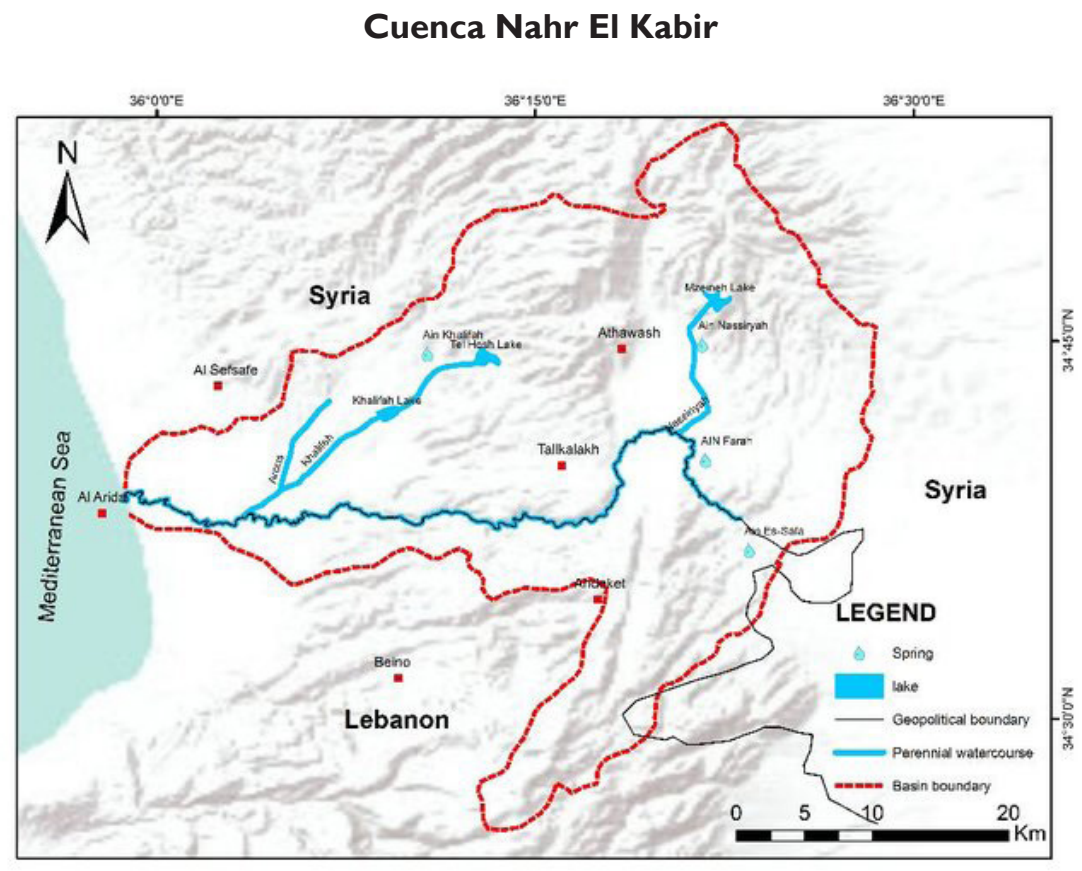

Fuente: Shaban y Hamzé, 2017.

\section{Descarga mensual promedio de la cuenca Nahr El Kabir}

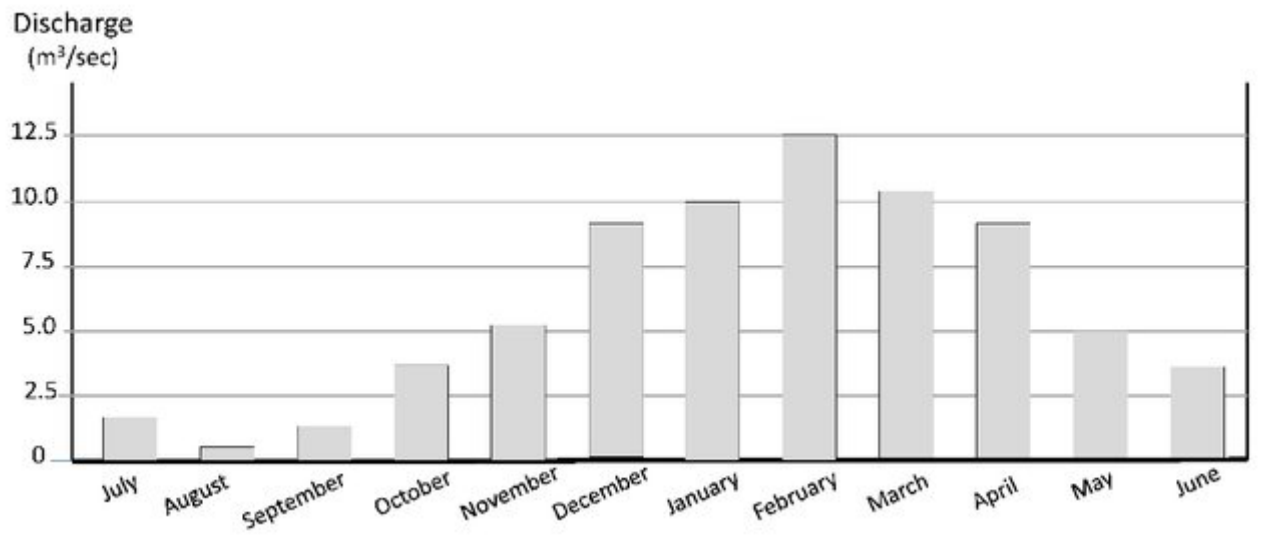

Fuente: Shaban y Hamzé, 2017.

\subsection{Acuífero Anti-Líbano}

En lo que respecta al agua subterránea, la cordillera Anti-Líbano se encuentra en la frontera libanesa-siria entre la llanura de Bekaa en el oeste y la llanura de Damasco en el este. La cordillera se extiende desde la llanura de Homs en el norte hasta más allá de su pico más alto, el Monte Hermón, en el sur. El Anti-Líbano es una fuente importante de agua, tanto localmente como en el contexto regional más amplio, ya que forma la fuente de varios ríos en el Mashrek. Varios manantiales grandes emanan de estos acuíferos y contribuyen a los ríos Awaj, Barada, Litani, Orontes y (Alto) Jordán. Existe una cooperación limitada entre Líbano y Siria sobre los recursos hídricos compartidos en el Anti-Líbano. 
La hidrología e hidrogeología de esta cadena montañosa con fallas profundas es muy compleja y poco conocida hasta la fecha, también en términos de la naturaleza transfronteriza de las cuencas de aguas superficiales y subterráneas. El agua subterránea en el Anti-Líbano se almacena principalmente en rocas de carbonato Jurásico y Cretácico (Cenomanian-Turonian) altamente fracturadas y karstificadas, que a menudo se extienden a través de las fronteras políticas. Varios manantiales grandes emanan de estos acuíferos y contribuyen a los ríos Awaj, Barada, Litani, Orontes y (Alto) Jordán (UN ESCWA y BGR, 20I3; OregonStateUniversity, 20I6).

No existen acuerdos de agua referidos a ningún sector de la cordillera Anti-Líbano, ni para las tres cuencas compartidas de los manantiales mencionados. Los dos países ribereños coordinan los problemas de gestión de los recursos hídricos compartidos a través del Comité Conjunto Sirio-Libanés para Agua Compartida, que también implementa los acuerdos vigentes sobre el río NahrAl Kabir y el río Orontes. Sin embargo, no está claro si los sistemas de acuíferos compartidos en la Cordillera del Líbano han sido abordados bajo este marco de cooperación. Todavía hay una comprensión limitada de los sistemas de acuíferos compartidos presentados en este capítulo, así como de otras cuencas de aguas superficiales y subterráneas en la Cordillera Anti-Líbano. Los países ribereños podrían beneficiarse de una cooperación más estrecha en el ámbito de la investigación conjunta sobre las cuencas compartidas, incluida la delimitación precisa de las zonas de captación y las zonas de protección, la determinación de los equilibrios hídricos y el posible impacto del cambio climático (UN ESCWA y BRG, 20I3).

Acuífero compartido de Anti-Líbano (con dirección de los flujos de aguas subterráneas)

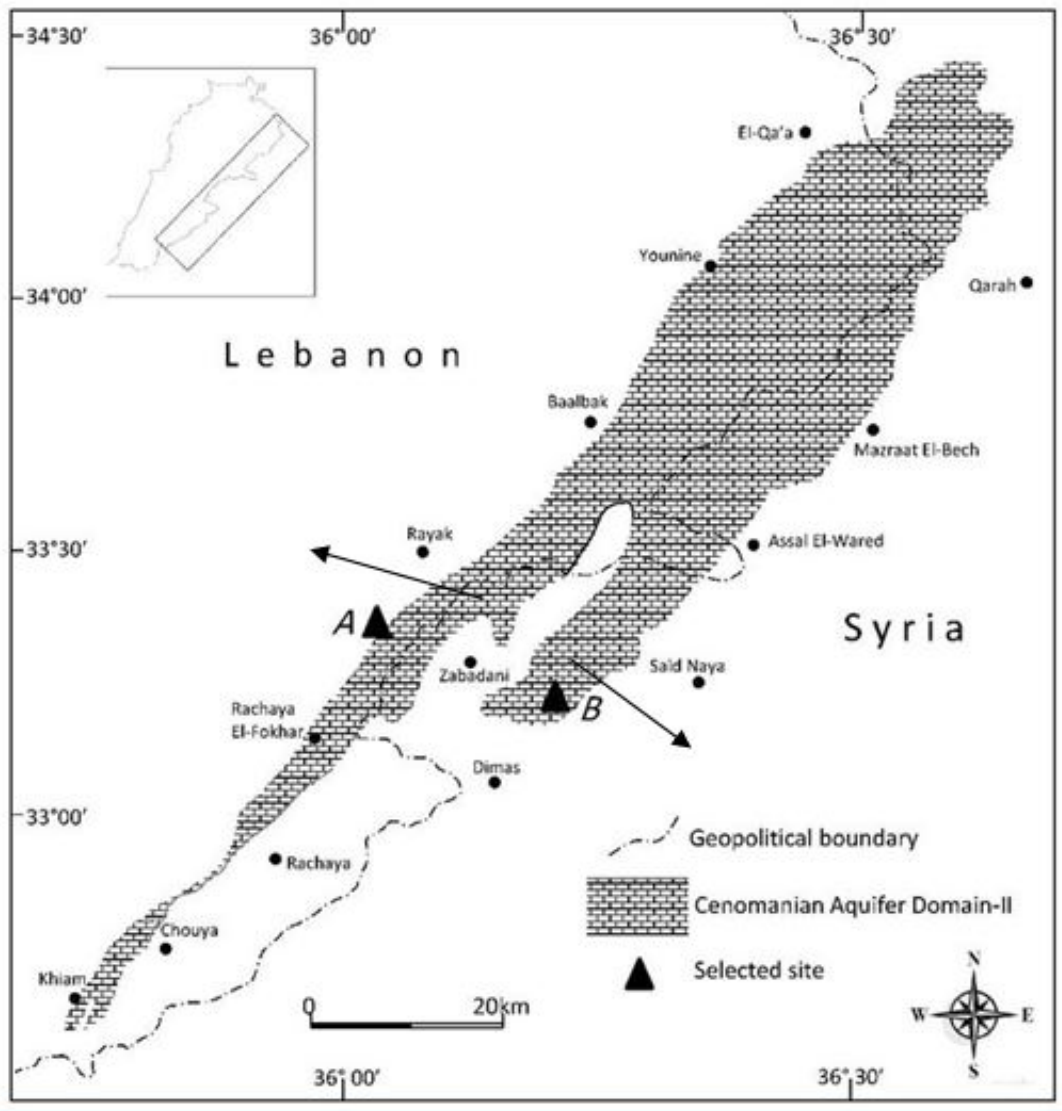

Fuente:Adaptado de Shaban y Hamzé, 2017. 
Cuadro comparativo de cuencas transfronterizas compartidas entre la República del Líbano y países ribereños

\begin{tabular}{|c|c|c|c|c|}
\hline $\begin{array}{c}\text { CUENCA } \\
\text { TRANSFRONTERIZA }\end{array}$ & $\begin{array}{c}\text { ORONTES (AL } \\
\text { ASI) }\end{array}$ & $\begin{array}{l}\text { NAHR AL } \\
\text { KABIR }\end{array}$ & JORDÁN & $\begin{array}{l}\text { ACUÍFERO ANTI- } \\
\text { LÍBANO }\end{array}$ \\
\hline PAÍSES RIBEREÑOS & $\begin{array}{l}\text { Líbano, Siria, } \\
\text { Turquía }\end{array}$ & Líbano y Siria & $\begin{array}{l}\text { Líbano, Israel, Jordania, } \\
\text { Palestina y Siria }\end{array}$ & Líbano y Siria \\
\hline $\begin{array}{l}\text { SUPERFICIE DE } \\
\text { LA CUENCA } \\
\text { COMPARTIDA }\end{array}$ & $\begin{array}{l}\text { Líbano } 8 \% \\
\text { Siria } 67 \% \\
\text { Turquía } 25 \%\end{array}$ & $\begin{array}{l}\text { Líbano } 26 \% \\
\text { Siria } 74 \%\end{array}$ & $\begin{array}{c}\text { Líbano } 4 \% \text {, Israel } 10 \% \text {, } \\
\text { Jordania } 40 \% \text {, Palestina } \\
9 \% \text {, Siria } 37 \%\end{array}$ & $\begin{array}{c}\text { Anjar-Chamsine, Barada, } \\
\text { Figeh }\end{array}$ \\
\hline $\begin{array}{c}\text { SUPERFICIE DE LA } \\
\text { CUENCA }\end{array}$ & $26.530 \mathrm{~km}^{2}$ & $954 \mathrm{~km}^{2}$ & $18.285 \mathrm{~km}^{2}$ & $\begin{array}{c}\text { Anjar-Chamsine: } 248 \mathrm{~km}^{2} \\
\text { Barada: I } 49 \mathrm{~km}^{2} \\
\text { Figeh: } 658 \mathrm{~km}^{2}\end{array}$ \\
\hline $\begin{array}{l}\text { LONGITUD DEL } \\
\text { RÍO }\end{array}$ & $404 \mathrm{~km}$ & $77,8 \mathrm{~km}$ & $223 \mathrm{~km}$ & - \\
\hline $\begin{array}{l}\text { APORTACIÓN } \\
\text { MEDIA ANUAL }\end{array}$ & $\mathrm{I}, 2 \mathrm{bm} / \mathrm{a}$ & $377 \mathrm{~mm}^{3} / \mathrm{a}$ & $\begin{array}{c}\text { Condiciones naturales } \\
\text { (1950s) } \\
\text { Alto río Jordán: } \\
605 \mathrm{~mm}^{3} / \mathrm{a} \\
\text { río Yamouk (subcuenca): } \\
450-500 \mathrm{~mm}^{3} / \mathrm{a} \\
\text { Bajo río Jordán: I } \\
300 \mathrm{~mm}^{3} / \mathrm{a} \\
\text { Condiciones actuales: } \\
\text { Alto río Jordán: } \\
616 \mathrm{~mm}^{3} / \mathrm{a} \\
\text { río Yarmouk: } 83-99 \mathrm{~mm}^{3} / \mathrm{a} \\
\text { Bajo río Jordán: } \\
20-200 \mathrm{~mm}^{3} / \mathrm{a} \\
\end{array}$ & - \\
\hline EMBALSES & $\begin{array}{l}9 \text { (cap. máx. de } \\
\text { almacenamiento } \\
\left.939 \mathrm{~mm}^{3} / \mathrm{a}\right)\end{array}$ & $\begin{array}{c}3 \text { (cap. máx. de } \\
\text { almacenamiento } \\
\left.75 \mathrm{~mm}^{3} / \mathrm{a}\right)\end{array}$ & $\begin{array}{c}45 \text { (cap. máx. de } \\
\text { almacenamiento } \sim 390 \\
\mathrm{~mm}^{3} / \mathrm{a} \text { ) }\end{array}$ & - \\
\hline $\begin{array}{c}\text { SUPERCIE } \\
\text { DE RIEGO } \\
\text { PROYECTADA }\end{array}$ & $\sim 300.000$ ha & $\sim 23.000$ ha & $100.000-150.000 \mathrm{ha}$ & - \\
\hline USOS DEL AGUA & $\begin{array}{c}\text { agrícola, } \\
\text { doméstico e } \\
\text { industrial }\end{array}$ & $\begin{array}{l}\text { agrícola, } \\
\text { doméstico e } \\
\text { industrial }\end{array}$ & $\begin{array}{c}\text { agrícola, doméstico e } \\
\text { industrial }\end{array}$ & $\begin{array}{c}\text { agrícola, doméstico e } \\
\text { industrial }\end{array}$ \\
\hline $\begin{array}{c}\text { POBLACIÓN DE LA } \\
\text { CUENCA }\end{array}$ & 5,86 mill. & 530.000 & 7,18 mill. & I80.000 aprox. \\
\hline
\end{tabular}




\begin{tabular}{|c|c|c|c|c|}
\hline ACUERDOS & $\begin{array}{l}\text { Acuerdo sobre } \\
\text { la distribución de } \\
\text { agua entre Líbano } \\
\text { y Siria (I994). } \\
\text { Memorando de } \\
\text { Entendimiento } \\
\text { para la } \\
\text { construcción } \\
\text { conjunta de } \\
\text { represa entre Siria } \\
\text { y Turquía (2009). } \\
\text { No hay un } \\
\text { acuerdo } \\
\text { trinacional. }\end{array}$ & $\begin{array}{c}\text { Acuerdo para } \\
\text { la construcción } \\
\text { conjunta de } \\
\text { represa entre } \\
\text { Líbano y Siria } \\
\text { (2002). }\end{array}$ & $\begin{array}{l}\text { Acuerdo sobre el uso del } \\
\text { río Yarmouk, incluyendo } \\
\text { la construccción de la } \\
\text { represa Wahdah y } 25 \\
\text { represas en Siria entre } \\
\text { Jordania y Siria (1953). } \\
\text { Acuerdo sobre el } \\
\text { Anexo Il del Tratado } \\
\text { de Paz entre Israel } \\
\text { y Jordania respecto } \\
\text { de la distribución y } \\
\text { almacenamiento de } \\
\text { agua de los ríos Jordán } \\
\text { y Yarmouk, llamando al } \\
\text { esfuerzo de prevenir la } \\
\text { contaminación del agua, } \\
\text { así como establecer un } \\
\text { Comité Conjunto (I994). } \\
\text { Israel y Palestina (OLP) } \\
\text { aceptaron en I } 995 \text { el } \\
\text { Art. } 40 \text { del acuerdo } \\
\text { político por el cual Israel } \\
\text { reconoce los derechos } \\
\text { de agua a Palestina } \\
\text { solo en Cisjordania, } \\
\text { y establece y Comité } \\
\text { Conjunto. Sin embargo, } \\
\text { los palestinos no tienen } \\
\text { acceso al río bajo este } \\
\text { acuerdo. }\end{array}$ & No existe acuerdo. \\
\hline
\end{tabular}

Fuente: Elaborado a partir de datos de: United Nations Economic and Social Commission for Western Asia (UN ESCWA) y Bundesanstalt für Geowissenschaften und Rohstoffe (BGR) (20I3). Inventory of Shared Water Resources in Western Asia. Beirut. Recuperado de: https://waterinventory.org/overview/shared-water-resources-western-asia (12.03.20I8).

\section{Conclusiones}

La República del Líbano está marcada por una historia de crisis política, institucional, social, económica, ambiental, pero sobre todo de gobernabilidad. De allí que la gobernanza, particularmente la ambiental, estéprácticamente ausente, con algunas interrupciones muy discontinuas basadas en financiación internacional que no terminan de materizalizarse en proyectos concretos en esta área.

Las movilizaciones sociales iniciadas en octubre de 2019 por reclamos estructurales al gobierno libanés, acusado de corrupción generalizada, se vieron interrumpidas por la pandemia global y vigorizadas el pasado 4 de agosto ante la tragedia en el puerto de Beirut, marcando, una vez más, heridas en el pueblo libanés, también en materia ecológica.

La conflictividad ha sido un elemento consustancial a la geopolítica de la región desde tiempos remotos, pero se visualizan nuevas oportunidades en el campo internacional de los recursos hídricos transfronterizos, en los que existen propuestas de avances hacia la cooperación, auspiciada por los principios de la gobernanza y la hidrodiplomacia, en el marco de una gestión integrada e integral de sus recursos naturales, en particular, hídricos. 
El desarrollo sostenible a largo plazo de cualquier cuenca, comprendida a partir del concepto de "unidad de cuenca", no se puede implementar sin un enfoque de gobernanza adecuado, basado en el uso compartido y razonable, que requiere que la gestión de este sistema debe ejercerse en un espíritu de participación, responsabilidad, eficacia, coherencia y, en especial, institucionalidad.

La adopción de la Convención de las Naciones Unidas sobre el Derecho de los Usos No Navegables de los Cursos de Agua Internacionalesotorgó ciertos beneficios al país en materia de cooperación binacional con Siria. Sería interesante que se avance en el mismo sentido con la Convención de la CEPE sobre la protección y el uso de los cursos de agua transfronterizos y los lagos internacionales, y así acogerse a los principios internacionales de la hidrodiplomacia.

La inestabilidad política de larga duración en la región ha obstaculizado, y aún obstaculiza, una cooperación exitosa a nivel de cuencas, entre otros aspectos. En el Medio Oriente no hay ningún acuerdo amplio sobre recursos hídricos compartidos, como tampoco sobre la calidad del agua, punto más crítico de los ríos de la región y clave para enfrentar la crisis sanitaria actual. La ineficiencia del sistema público de distribución de agua y del manejo de aguas residuales es otro gran tema pendiente, teniendo en cuenta la constante presión que ejercen las masas migratorias de refugiados en el pequeño territorio libanés. El replanteo de estas cuestiones es fundamental, en especial, ante el décimo aniversario de la Resolución de la Asamblea General de ONU sobre el Derecho Humano al Agua y al Saneamiento.

Resulta preciso y urgente impulsar la educación y la conciencia, de la mano de la cultura ambiental en un país y en una región en donde, históricamente, han prevalecido otras necesidades. Tristemente, el Líbano continúa experimentando el daño ecológico generalizado, viendo afectada así la sustentabilidad de la vida digna.

\section{Referencias}

Aguilar, G. e Iza, A. (2009). Gobernanza de Aguas Compartidas: Aspectos jurídicos e institucionales. IUCN Environmental Policy \& Law Paper $\mathrm{N}^{\circ} 58 \mathrm{rev}$. Gland: International Union for Conservation of Nature.

Barrington, L.y Williams, D. (2018). Israel, Lebanon clash over offshore energy, raising tensions. Reuters. Recuperado de: https://www.reuters.com/article/us-natgas-lebanon-israel/israel-lebanon-clash-over-offshore-energy-raising-tensions-idUSKBNIFKIJ0 (28.04.2020).

Elias, G. (20I4). Consecuencias económicas y ambientales de la Guerra del Líbano de 2006. Anuario del Instituto de Relaciones Internacionales (IRI), Facultad de Ciencias Jurídicas y Sociales, Universidad Nacional de La Plata. $N^{\circ}$ 20. ISSN 2347-0674.

Elias, G. (2016). La protección del medio ambiente en tiempo de conflicto armado. Un análisis del Derecho Internacional Humanitario. Estudio de caso: Consecuencias ambientales y económicas de la Guerra del Líbano de 2006. Cuadernos de Martes. Revista latinoamericana de sociología de la guerra. Instituto de Investigaciones Gino Germani, Facultad de Ciencias Sociales, Universidad de Buenos Aires. X Año 7. ISSN: I852- 9879.

Elias, G. (2019). Por un Derecho Humano Universal al Agua y al Saneamiento. Centro de Estudios en Políticas Ambientales, Facultad de Ciencia Política y Relaciones Internacionales, Universidad Nacional de Rosario. Recuperado de:https://cepasunr.wordpress.com/2019/07/04/por-un-derecho-humano-universal-al-agua-y-al-saneamiento/ (25.02.2020).

Global Water Partnership (GWP) (2000). Integrated Water Resources Management. Technical Advisory Committee (TAC) Background Paper $n^{\circ}$ 4. Stokholm: GWP.

GWP e International Network of Basin Organizations (INBO)(20I2). Manual para la gestión integrada de los recursos hídricos de las cuencas transfronterizas de ríos, lagos y acuíferos. París.

Instituto de Desarrollo Rural (IDR)(s/f). Diccionario de vocablos geográficos y cartográficos. Mendoza. Recuperado de: http://www.ecoatlas.org.ar/pdf/vocablos_geograficos_cartograficos.pdf (25.03.2020).

Keohane, R. O. (1984). After hegemony: cooperation and discord in the world political economy. Princeton, N.J.: Princeton 
UniversityPress.

Mello Sant'anna, F.y Villar, P. (20I5). Gobernanza de las aguas transfronterizas: fragilidades institucionales. América Latina Hoy: Revista de Ciencias Sociales, 69. Salamanca: Instituto de Iberoamérica de la Universidad de Salamanca.

Ministry of Environment, Republic of Lebanon (2012). Water sector. Recuperado de: http://www.moe.gov.lb/Sectors/ Water.aspx(25.02.2018).

Naciones Unidas (1997). A/RES/5 I/229 Convención sobre el derecho de los usos de los cursos de agua internacionales para fines distintos de la navegación. Nueva York.

Naciones Unidas (20I4). Decenio Internacional para la Acción “El agua fuente de vida 2005-20I5”. Recuperado de: http:// www.un.org/spanish/waterforlifedecade/transboundary_waters.shtml(20.07.20I7).

Oregon State University; College of Earth, Ocean, and Atmospheric Sciences (2016). Transboundary Freshwater Dispute Database. Oregon.

Paisley, R. (2008). FAO Training Manual for International Watercourses/ River Basins Including Law, Negotiation, Conflict Resolution and Simulation Training Exercises. FAO.Vancouver: University of British Columbia.

Rahaman, M. M. (2009). Principles of International Water Law: Creating Effective Transboundary Water Resources Management. International Journal Sustainable Society, I (3). Espoo: Helsinki University of Technology.

Saguier, M. (2017). Transboundary water governance in South America. En Riggirozzi, P. yWylde, C. (eds.) Handbook of South American Governance.United Kingdom: Routledge.

Shaban, A. y Hamzé, M. H. (20I7). Shared Water Resources of Lebanon. Nueva York: Nova Science Publishers, Inc. ISBN: 978-I-536|2-|42-I. Recuperado de: https://www.researchgate.net/publication/319980038 Shared Water Resources_of_Lebanon (03.05.2020).

Siegel, K. (2017). Regional Environmental Cooperation in South America: Processes, Drivers and Constraints. International Political Economy Series. Londres: Palgrave Macmillan.

United Nations Economic Commission for Europe (UNECE) (2019). Lebanon steps closer towards accession to the Water Convention. Recuperado de: https://www.unece.org/info/media/news/environment/2019/lebanon-steps-closer-towards-accession-to-the-water-convention/doc.html (28.04.2020).

United Nations Economic and Social Commission for Western Asia (UN ESCWA) and Bundesanstalt für Geowissenschaften und Rohstoffe (BGR) (20I3). Inventory of Shared Water Resources in Western Asia. Beirut. Recuperado de: https://waterinventory.org/overview/shared-water-resources-western-asia (I 2.03.20I8).

UNESCO, International Hydrological Programme (IHP) (2016). Hydrodiplomacy, legal and institutional aspects of water resources governance. From the international to the domestic perspective.Training manual. París: UNESCO.

United Nations Environmental Programme (UNEP) (2007). Lebanon. Postconflict Environmental Assesment. Nairobi.

Villar, P. C. y Ribeiro Costa, W. (20I I). The Agreement on the Guarani Aquifer: a new paradigm for transboundary groundwater management? Water International, vol. 36 (5), pp. 646-660. DOI: http://dx.doi.org/ / 0.1080/0250 8060.2011 .60367

Walnycki, A. (19.02.2018). Getting Lebanon's water flowing: using new SDG data in an urban crisis. International Institute for Environment and Development (IIED).Recuperado de: https://www.iied.org/getting-lebanons-water-flowing-using-new-sdg-data-urban-crisis (25.02.2018).

Warner, J. y Zawahri, N. (20I2). Hegemony and asymmetry: multiple-chessboard games in transboundary rivers. International Environmental Agreements, vol. 12 (3), pp. 21 5-229.

Wolf, A. T. (2007). Shared waters: Conflict and Cooperation. The Annual Review of Environment and Resources. 32: 24I-69. First published online as a Review in Advance on July 3I, 2007.

Yoffe, S.;Wolf,A. y Giordano, M. (2003). Conflict and cooperation over international freshwater resources: indicators of basins at risk. Journal of the American Water Resources Association, vol. 39 (5), pp. I I09-I I 26. DOI: http:// dx.doi.org/I0.I I I I/j. I752-I688.2003.tb03696.x

Zeitoun, M. y Mirumachi, N. (2008). Transboundary water interaction I: reconsidering conflict and cooperation. International Environmental Agreements: Politics, Law and Economics, Springer, vol. 8 (4), pages 297-3 I6, December. DOI 10.1007/s 10784-008-9083-5

Zeitoun, M. y Mirumachi, N. (2010). Transboundary water interaction: reconsidering conflict and co-operation. En Wegereich, K. y Warner, J. (eds.). The politics of water: a survey. Londres: Routledge, pp. 96-I 18.

Zeitoun, M.; Mirumachi, N.y Warner, J. (20II). Transboundary water interaction II: the influence of soft power. International Environmental Agreements-Politics Law and Economics, vol. II (2), pp. I 59-I 78.

$52^{\circ}$ Conferencia de la Asociación de Derecho Internacional (1966). Normas de Helsinki sobre los usos de las aguas de los ríos internacionales. Helsinki. 


\section{RELACIONES INTERNACIONALES}

Revista académica cuatrimestral de publicación electrónica

Grupo de Estudios de Relaciones Internacionales (GERI)

Universidad Autónoma de Madrid, España

https://revistas.uam.es/relacionesinternacionales

ISSN 1699 - 3950

f facebook.com/RelacionesInternacionales

3. twitter.com/RRInternacional 